\title{
Self-centering behavior of unbonded precast concrete shear walls
}

\author{
B. Erkmen \& A. E. Schultz \\ University of Minnesota, USA
}

\begin{abstract}
Concrete shear walls are a cost-effective way of providing lateral load resistance for structural systems located in seismic regions. If concrete shear walls are precast and rely on unbonded post-tensioned tendons for flexural reinforcement, then the structural damage observed in conventionally reinforced cast-in-place shear walls arising from tensile stress transfer can be avoided altogether. Over the past decade, it has been recognized that excellent seismic performance of precast concrete shear walls can be mobilized by utilizing post-tensioned unbonded vertical reinforcement in precast shear walls to create extensible connections that allow controlled rocking. Another important advantage of posttensioned precast concrete shear walls, and one which has not been studied extensively, is their superior self-centering characteristic. The self-centering property of unbonded post-tensioned walls is generally attributed to the presence of the post-tensioning force. However, the experimental results presented in this study indicate that the post-tensioning force may completely die out during cyclic loading while the wall retains its self-centering characteristic. Moreover, analytical study, verified with experimental results, indicates that with proper design of end-anchorages for post-tensioned tendons, self-centering can be achieved even when the post-tensioning force dies out completely. The study summarized here investigates the self-centering ability of unbonded precast concrete shear walls, particularly the effects of post-tensioning force, tendon layout, and the end-anchorage detail.

Keywords: seismic performance, self-centering, unbonded tendons, precast concrete, shear walls, post-tensioning.
\end{abstract}




\section{Introduction}

Conventional concrete shear walls that are a part of monolithic structures are expected to undergo significant structural damage (flexural and shear cracking, toe crushing, and rebar fracture and buckling) and residual lateral displacement during seismic events. Thus, the economic impacts of the associated seismic damage can be significant. Precast concrete shear wall structures, on the other hand, are significantly different in terms of expected structural behavior. As such, different design philosophies have been developed for precast structures in the USA [1,2] where precast concrete structural systems fall into two design categories. The first design one is "emulation construction", in which precast structures are detailed to emulate monolithic reinforced concrete structural systems. The second alternative is "jointed construction", in which precast members are interconnected predominantly by dry joints (i.e., requiring no concrete to be cast at the site).

In general, the non-emulative design philosophy is preferred as it allows certain joints between the precast members to undergo inelastic deformations without significant damage. This inherent characteristic can be used for seismic resistance. For precast shear wall, joints between panels may open and close, and undergo inelastic deformations without significant damage. These locations provide deformation capacity and, possibly, energy dissipation in precast structural systems [3].

Over the past decade, it has been recognized that the seismic performance of precast concrete structures can be improved if the flexural reinforcement is posttensioned and placed inside ducts that are left ungrouted (i.e., unbonded). Due to the lack of bond between reinforcement and concrete, damage is not introduced in the concrete through bond stress transfer from the reinforcement [3, 4-7]. However, there is limited information related to their self-centering capability precast walls. Their self-centering capability has generally been attributed to the presence of post-tensioning force, which has led to concerns that the posttensioning force may significantly decrease or completely die out during seismic loading as the wall rocks and the tendon is elongated. However, this relationship and its underlying causes have not been investigated explicitly, and a detailed investigation of the self-centering mechanism of precast shear walls is needed.

\section{Background}

Figure 1 shows a test specimen representing a typical post-tensioned precast concrete shear wall with tendons that are placed in ducts and left unbonded over wall height. During erection, the only wet concrete that is used is dry-pack grout between panels, footings and floor slabs. The only locations where wet concrete is placed during erection are the connection surfaces between wall panels, or between the panels and footing or floor slabs, where dry-pack grout is used to fill the gaps and provide uniform bearing stress transfer. 


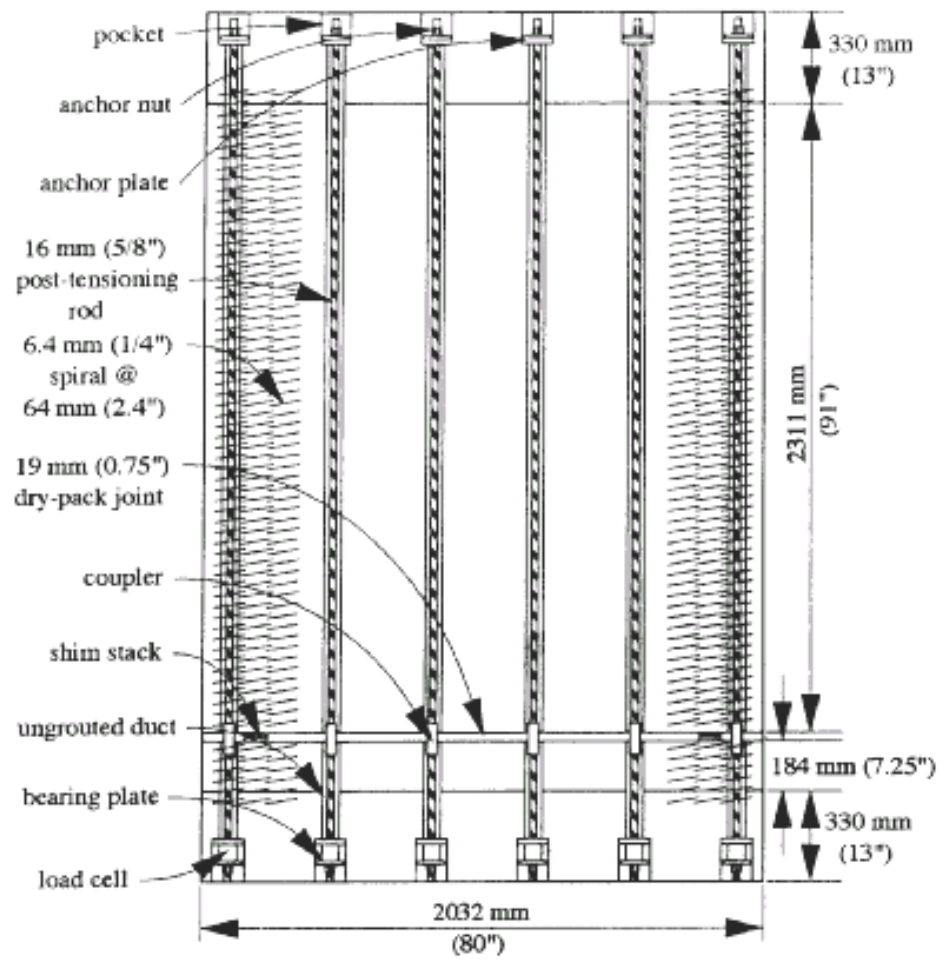

Figure 1: $\quad$ Test specimen of unbonded, post-tensioned precast shear wall.

Unbonded tendons are anchored to the wall panels only at anchorage and tensioning locations, of which feature eliminates bond stress transfer and the associated tensile cracking damage in the concrete. For the case of oversize ducts and straight tendons, friction losses are negligible, and the uniform strain distribution along the tendons delays tendon yielding and rupture. Under seismic loading, the loading and unloading branches of the force-displacement relation are close to each other by virtue of small amount of damage to the materials. And, upon unloading, little residual drift is observed.

An extensive research program conducted in the USA to utilize the concept of jointed precast concrete structures [8] has shown that unbonded, post-tensioned shear walls can be used as the primary lateral load carrying element in regions of high seismicity. This study culminated with a series of pseudo-dynamic tests of a large-scale (1:0.6) five-story precast concrete building. The behavior of the unbonded precast shear wall was excellent, with only minor non-structural damage in the loading direction that included shear walls. The residual drifts in the wall direction after design level excitation did not exceed $0.06 \%$ after sustaining a top drift of $1.8 \%$ of structure height. 


\section{Experimental investigation}

Schultz et al. [3] conducted an experimental investigation, as part of the PRESSS program, investigate the characteristics of connection regions in jointed precast shear walls. One shear wall specimen (PTT), which featured unbonded, posttensioned tendons (PTT) at a horizontal joint, was a $2 / 3$-scale representation of the lowest two stories of a prototype precast concrete shear wall in a six story precast office building. Concrete with a compression strength of $34.5 \mathrm{MPa}$ $(5,000 \mathrm{psi})$ was used in conjunction with $1,124 \mathrm{MPa}(163 \mathrm{ksi})$ post-tensioning bars, the latter which were spliced using standard couplers. The vertical bars were placed in oversized ducts and anchored to the walls at the top and at the foundation level. A $19 \mathrm{~mm}(3 / 4 \mathrm{in}$.) thick layer of high-strength dry-pack mortar was placed between panels at horizontal joints.

Six tendons with a $16 \mathrm{~mm}(5 / 8 \mathrm{in}$.) diameter were uniformly placed in the connection region, even though PRESSS recommendations suggest tendon placement near the middle of the wall to protect them from large tension strains. Uniform distribution was used to limit out-of plane movement. The bars were initially post-tensioned to $60 \%$ of tendon strength (i.e., $695 \mathrm{MPa}, 95 \mathrm{ksi}$ ). Spiral reinforcement was provided at the edges of the panels to confine the concrete as large compression strains were expected in these regions due to wall rocking.

Specimen PTT was tested at the National Institute of Standards and Technology (NIST) using the Tri-directional Test Facility (TTF) [9] under quasistatic loading. In-plane horizontal drift and overturning moment were applied to specimen PTT, in addition to a constant vertical load for a net vertical compression stress equal to $689 \mathrm{~Pa}(100 \mathrm{psi})$.

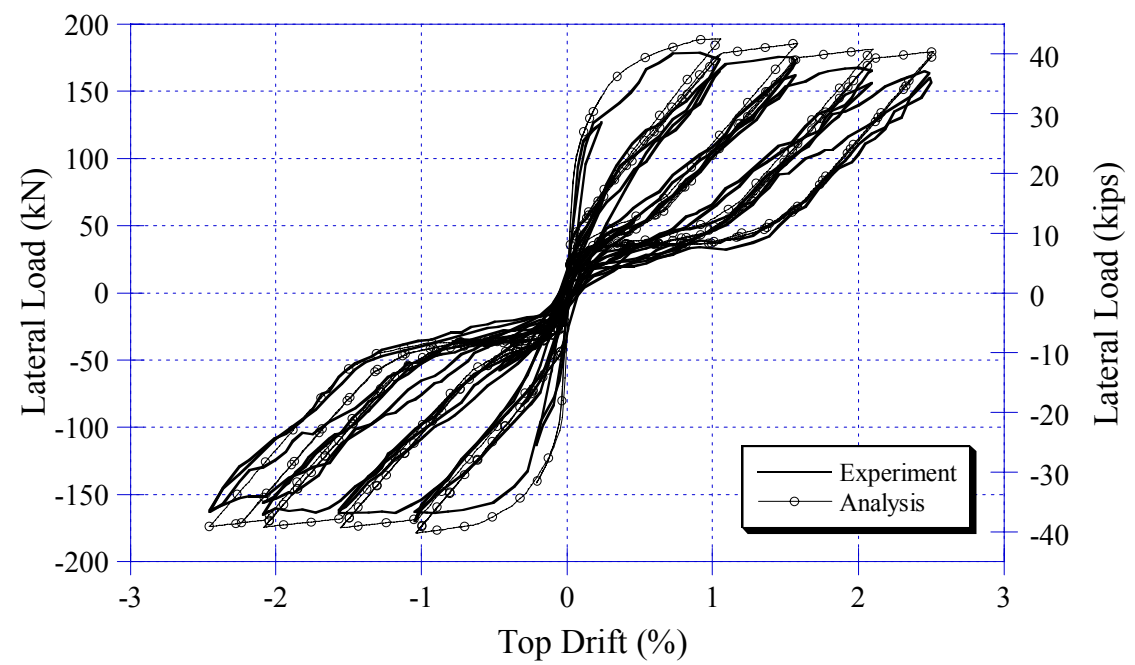

Figure 2: $\quad$ Specimen PTT experimental and analytical response. 


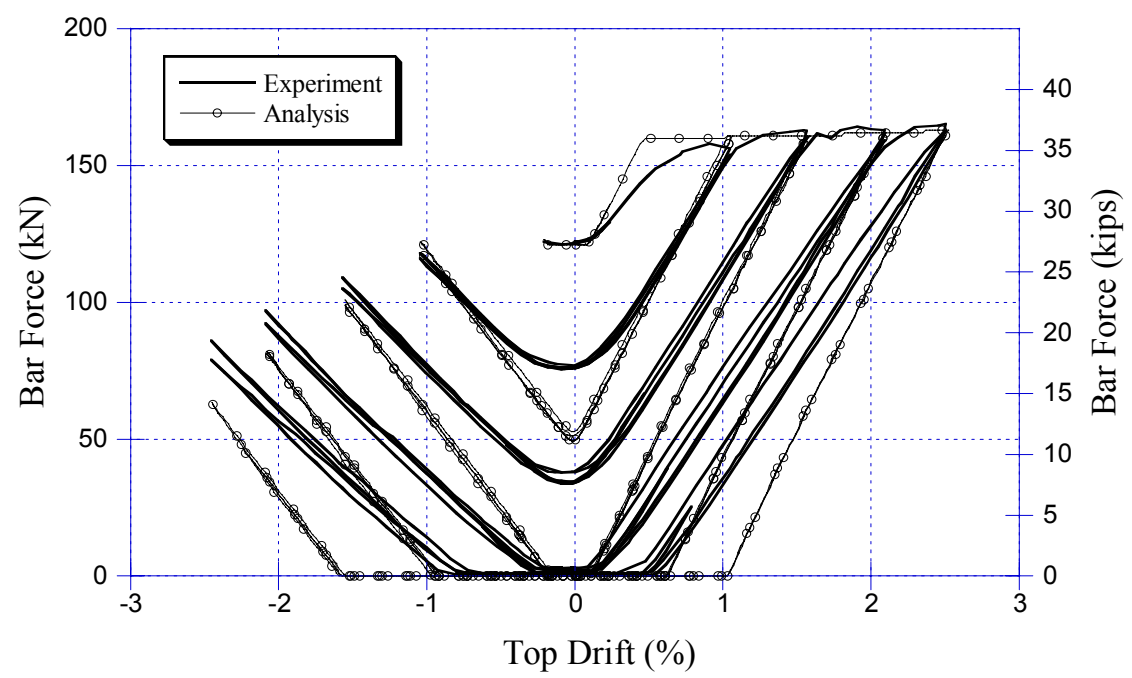

Figure 3: Bar force-drift relationship for tendon EI.

The overturning moment at the top of the specimen represented the continuity moment at an elevation equal to one-third of total wall height from the base of the prototype six-story shear wall.

The lateral force-drift response of specimen PTT (Fig. 2) was stable with small, but finite energy dissipation capacity and good self-centering capacity. High initial stiffness and linear behavior were observed until a gap began to open along the horizontal joint, after which the behavior became nonlinear. The stiffness of the wall, at a drift of approximately $0.2 \%$, started to decay gradually due to both yielding of the reinforcement and gap opening at the joint region. The peak lateral load capacity of $178 \mathrm{kN}$ (40 kips) was maintained throughout the loading history despite the fact that most tendons lost their post-tensioning force by the end of the loading history (Fig. 3). In spite of the decay in both stiffness and post-tensioning force, the wall preserved its self-centering ability during the test, with almost no residual displacement up to a maximum drift of $2.5 \%$. The test was stopped because the stroke capacity of actuators was reached.

\section{Analytical modeling}

Nonlinear static analyses of specimen PTT were carried out using a model developed with the DRAIN-2DX program [10]. Kurama et al. [11] first described the use of DRAIN-2DX for the analysis of precast concrete shear walls with unbonded, post-tensioned tendons. Four types of elements (truss, concrete fiber, rigid link, and tension link) were used. Concrete fiber elements served to model the wall panels and they did not include reinforcement because the unbonded post-tensioning tendons were the only reinforcement placed continuously through the horizontal joint. Vertical and horizontal non- 
prestressed reinforcement were not continuous beyond panel edges. Truss elements were used to model the post-tensioning tendons, and these elements were not connected (i.e., unbonded) to the concrete panels. A rigid link element was used at the top of the wall to connect the degrees of freedom of the truss elements (i.e., tendons) to those of the fiber elements (i.e., wall panels) and ensure compatibility. Tension link elements (rigid in tension and slack in compression) were used at the ends of each tendon to prevent them from developing compression. The tendons did not bear against any surface beyond the anchor plates to develop such compression resistance (Fig. 1).

The load sequence included an initial application at the top of the wall of a constant vertical load of $214 \mathrm{kN}$ (48.0 kips), $13 \mathrm{kN}$ (3.0 kips) of which was wall weight. Then a post-tensioning force of $121 \mathrm{kN}$ (27.3 kips), which was slightly higher than the test value $118 \mathrm{kN}$ (26.6 kips), was applied to each tendon. The post-tensioning force decreased to the test value upon application due to elastic shortening of the concrete. The experimental cyclic lateral drift and top moment histories were applied next to obtain the response of the wall (Fig. 2). No significant differences in stiffness, lateral load capacity and absorbed energy are observed in the computed response relative to that measured in the experiments. Most importantly, the self-centering behavior of the model shows good fidelity with the experimental results.

Figure 3 shows the computed and measured force versus lateral displacement relationships for the third tendon (EI), from the left edge of the specimen. The force-drift curve for tendon EI predicted with the DRAIN-2DX model is slightly stiffer than that obtained from the experiment, specifically in unloading branches where the specimen exhibited stiffness degradation with increasing drift. Figure 3 also indicates that the post-tensioning force vanished at a drift ratio equal to zero after the drift ratio had achieve a value of approximately $2.2 \%$. This means that the remaining tendons lost their post-tensioning force at smaller drift values given their proximity to the edges of the panel. Yet, specimen PTT exhibited good self-centering behavior through all of the cycles at $2.5 \%$ drift, even though all of the post-tensioned force was lost for drift values larger than $2.2 \%$.

\section{Self-centering ability of post-tensioned shear walls}

The superior self-centering behavior of unbonded, post-tensioned walls is, in general, attributed to the presence of a finite post-tensioning force. However, the experimental and analytical findings presented suggest that post-tensioning force is not the only source of self-centering behavior. Vertical compression is generated by permanent loads (e.g., wall weight plus any additional dead load), semi-permanent loads (e.g., live loads), and transient loads (e.g., loads associated with vertical seismic excitation). In the case of specimen PTT, wall weight and external compression provided $214 \mathrm{kN}$ (48 kips) of constant vertical load which was present to resist lateral loading even when post-tensioning force vanished. 
The effect of several structural design parameters on the self-centering response of specimen PTT are investigated below. These parameters include: (1) tendon end-anchorage detail; (2) initial tendon stress; and (3) tendon location.

\subsection{Tendon end-anchorage detail}

The tendons used for specimen PTT (Fig. 1) were anchored in pockets which did not allow bearing of the tendon ends, such that the bars could not develop compression once the post-tensioning force died out. Tendons with anchorages that cannot undergo compression are referred to as "compression-prevented" tendons, whereas tendons with anchorages that allow compression are referred to as "compression-allowed" tendons. Thus, a variation of the analytical model for specimen PTT was developed which did not include the "rigid-slack" link elements described earlier, such that the tendons were modeled as "compressionallowed" to investigate the effect of the end-anchorage detail on wall behavior. Figure 4 shows the force-displacement response predicted by the model with compression-allowed tendons.

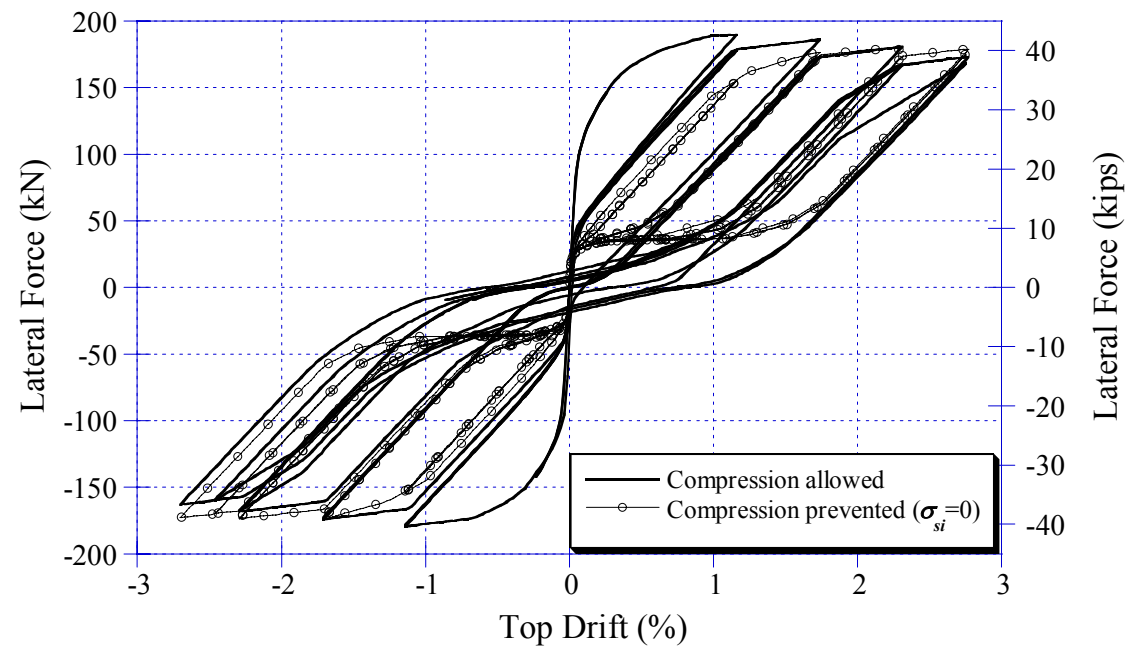

Figure 4: Predicted response of specimen PTT with tendons that develop compression, or tendons that do not develop compression (but have no initial prestress).

Despite the presence of the post-tensioning force, the predicted self-centering behavior of the wall with compression allowed tendons is inferior to that of the wall with compression prevented-tendons (Fig. 3). This difference is due to permanent elongation of the compression-allowed tendons, which take place at large drifts when the post-tensioning force has vanished. 


\subsection{Initial tendon stress}

Another variation of the DRAIN-2DX model of specimen PTT was used to investigate the effect of the magnitude of post-tensioning stress on self-centering behavior. For that case, no post-tensioning force was applied to the tendons $\left(\sigma_{s i}=0\right)$ which were modelled as "compression-prevented". Figure 4 shows the predicted lateral force-top drift response of the wall for such conditions.

The absence of initial post-tensioning force resulted in large reductions in initial stiffness and energy dissipation during cyclic loading. However, the model preserved its superior self-centering behavior despite the absence of posttensioning force. The presence of axial load and compression-prevented tendons was sufficient to preserve the self-centering behavior of the wall under cyclic loading. Tendons that are initially unstressed, but snug tight (i.e., with no slack), develop force as soon as the horizontal joint opens under lateral loading.

\subsection{Tendon location}

Two additional variations of specimen PTT were modeled by varying tendon location. In the first model, the outermost tendons on both sides of the wall were removed, and the area of the remaining two tendons (i.e., centered tendons) was tripled. The modified wall had the tendons were concentrated over the middle of wall length. In the second model, the four tendons closest to the wall center were removed, and the area of the two outermost tendons (i.e., edge tendons) was tripled. Thus, the tendons were concentrated along the wall edges. In both cases the tendons were not allowed to develop compression.

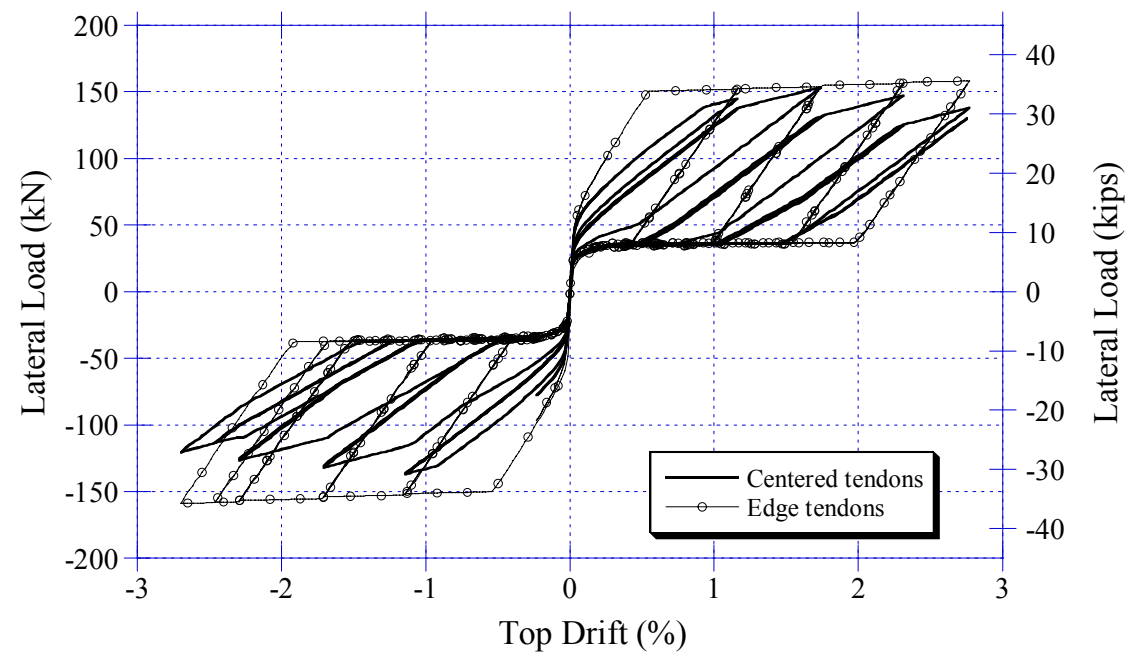

Figure 5: Predicted response of specimen PTT with compression-prevented tendons that are placed in the center of the wall, or along the edges. 
The predicted lateral load-drift relationships for the "centered tendon" and "edge tendon" models of the wall are presented in Fig. 5. The stiffness and energy absorption capacities of "centered tendon" model are considerably smaller than those of the "edge tendon" model, or even the original model (Fig. 2). These differences are due to the reduction in tendon arm (i.e., distance from tendon to wall center) which decreases tendon strain change per unit of gap opening. However, the response of the walls indicates that moving the tendons towards the center or the edge of the wall does not affect self-centering behavior.

\section{Conclusions}

Based on the experimental observations cited and the results predicted by the analytical models developed in this study, the following conclusions are made:

1. The DRAIN-2DX modeling techniques described here can be used to predict the lateral load response of precast concrete shear walls with unbonded, post-tensioned tendons.

2. Unbonded, post-tensioned precast concrete shear walls rely on the total combination of post-tensioning force, wall weight and net external vertical compression load to develop resistance to lateral loads as well as selfcentering ability.

3. The end-anchorage detail of unbonded tendons can significantly affect the hysteresis and self-centering behavior of unbonded walls.

4. Initial post-tensioning force has negligible effect on self-centering behavior of unbonded walls if the tendons are compression-prevented.

5. The distribution of tendons has negligible effect on self-centering behavior of the walls, but it may significantly affect the lateral stiffness and energy absorption capacity of the walls.

\section{Acknowledgements}

This work was supported in part by the Precast/Prestressed Concrete Institute (PCI) through a Daniel P. Jenny Fellowship and by the Department of Civil Engineering at the University of Minnesota through a Sommerfeld Fellowship. The authors wish to thank Professor Yahya Kurama from the University of Notre Dame for providing the modified DRAIN-2DX code.

\section{References}

[1] International Building Code, International Code Committee, Whittier, CA, 2006.

[2] NEHRP Recommended Provisions for Seismic Regulations for New Buildings and Other Structures (FEMA 450), 2003 Edition, Building Seismic Safety Council, Washington, DC, 2004. 
[3] Schultz, A., Cheok, G., and Magana, R., "Performance of Precast concrete Shear Walls", Proc., $6^{\text {th }}$ U.S. Nat. Conf. on Earth. Engrg., EERI, Oakland, CA, 1998.

[4] Cheok, G. S., Stone, W. C., and Lew, H.S., "Seismic performance behavior of precast concrete beam-column joints," Proc., Symp. on Struct. Engrg. in Nat. Haz. Mit., ASCE:Reston, VA, pp. 83-88, 1993

[5] Priestley, M.J.N. and Tao, J.R.T., "Seismic Response of Precast Prestressed Concrete Frames with Partially Debonded Tendons", PCI Journal, 38(1), pp. 58-69, 1993.

[6] Kurama, Y., Pessiki, S., Sause, R., Lu, L.-W., and El-Sheikh. M., "Analytical Modeling and Lateral Load Behavior of Unbonded PostTensioned Precast Concrete Walls", Rep. No. EQ-96-02, Dept. of Civil and Envir. Engrg., Lehigh University, Bethlehem, PA 1996, 191 pp.

[7] Holden, T.J., "A comparison of the seismic performance of precast wall construction: emulation and hybrid approaches," Res. Rep. 2001-04, ISSN 0110-3326, University of Canterbury, Christchurch, New Zealand.

[8] Priestley, M. J. N, Sritharan, S., Conley, J. R., and Pampanin, S., "Preliminary Results and Conclusions from the PRESSS Five-Story Precast Concrete Test Building” PCI Journal, 44(6), pp. 42-67, 1999.

[9] Woodward, K., and Rankin, F., " The NBS TRI-Directional Test Facility”, NBSIR 84-2879, U.S. Dept. of Comm., Nat. Bur. of Stds., Gaithersburg, MD, 1984.

[10] Prakash, V., and Powell, G., "DRAIN-2DX Base program Description and User Guide; Version 1.10”, Rep. No. UCB/SEMM-93/17, Dept. of Civil Engrg., Univ. of Calif., Berkeley, 1993.

[11] Kurama, Y., Sause, R., Pessiki, S., Lu, L.-W., and El-Sheikh, M. "Seismic Design and Response Evaluation of Unbonded post-Tensioned Precast Concrete Walls", Res. Rep. No. EQ-97-01, Dept. of Civil and Envir. Engrg., Lehigh University, 1997, 184 pp. 